\section{Determinan Nilai Perusahaan Pada Subsektor Makanan Dan Minuman Periode 2016-2018}

\author{
Jessica Bintang Glory $^{1)}$, Fitri Yetty ${ }^{2)}$, Nunuk Triwahyuningtyas ${ }^{3)}$ \\ Fakultas Ekonomi dan Bisnis, \\ Universitas Pembangunan NasionalVeteran Jakarta \\ Email:-1jessicabintangs@gmail.com ²itriyetty_61@yahoo.com, \\ ${ }^{3}$ nunukwowo@gmail.com
}

Company Value
and Food Beverage
Manufacture

239

Submitted: SEPTEMBER 2020

Accepted: NOVEMBER 2020

\begin{abstract}
The purpose of this research is to examine the influence of capital structure with the calculation of Debt Equity Ratio (DER), Profitability with the proxy of Return On Equity (ROE) and Company Size with the proxy of Size calculations on the company's value with the calculation of Price Book Value (PBV) of the company's food and beverage subsectors listed on the Indonesia Stock Exchange. The data used is secondary data with a sample collection method using purposive sampling. Where the population of this study used is the food and beverage subsectors company listed on the Indonesia Stock exchange with a period of observation 2016 - 2018, with the final samples of research 12 companies selected. Data analysis techniques are conducted using descriptive statistics and data regression analysis panels with the help of E-Views version 10 and Microsoft Excel applications 2013. The results of the research are partially known that the company structure (DER) affects on the company's value (PBV), profitability (ROE) affects the company's value and the Company Size has no effects to the company's value. As well as independent variables explain the dependent variable by $91.76 \%$
\end{abstract}

Keywords: Capital Structure, Profitability, Company Size and Company Value

\begin{abstract}
ABSTRAK
Tujuan dari penelitian ini ialah untuk menguji pengaruh dari struktur modal dengan proksi perhitungan Debt to Equity Ratio (DER), Profitabilitas dengan proksi perhitungan Return On Equity (ROE), dan Ukuran Perusahaan dengan proksi perhitungan Size terhadap nilai perusahaan dengan proksi perhitungan Price Book Value (PBV) perusahaan subsektor makanan dan minuman yang terdaftar di Bursa Efek Indonesia. Data yang digunakan adalah data sekunder dengan metode pengumpulan sampel menggunakan purposive sampling. Dimana populasi penelitian ini yang digunakan adalah perusahaan subsektor makanan dan minuman yang terdaftar di Bursa Efek Indonesia dengan periode pengamatan 2016 - 2018 dengan sampel akhir penelitian 12 perusahaan terpilih. Teknik analisis data dilakukan menggunakan statistik deskriptif dan analisis regresi data panel dengan bantuan aplikasi E-Viewsversion 10 dan Microsoft Excel 2013. Hasil penelitian secara parsial diketahui bahwa Struktur Modal (DER) berpengaruh terhadap Nilai Perusahaan (PBV), Profitabilitas (ROE) berpengaruh terhadap Nilai Perusahaan dan Ukuran Perusahaan (Size) tidak berpengaruh terhadap Nilai Perusahaan. Serta variabel independen menejelaskan variabel dependen sebesar $91,76 \%$
\end{abstract}

Kata Kunci: Struktur Modal, Profitabilitas, Ukuran Perusahaan, dan Nilai Perusahaan

\section{JIMKES}

Jurnal Ilmiah Manajemen Kesatuan Vol. 8 No. 3,2020 pp. $239-248$ IBI Kesatuan
ISSN $2337-7860$ E-ISSN $2721-169 \mathrm{X}$ 
Company Value and Food Beverage Manufacturer

\section{PENDAHULUAN}

Perusahaan memiliki tujuan utama yang ditempuh dalam rentan waktu yang panjang, yaitu untuk memaksimalkan nilai perusahaan dengan meminimalisasi atau menekan habis biaya modal perusahaan. Nilai perusahaan yang berada di atas rata-rata atau optimal mengartikan bila perusahaan tersebut memiliki kemampuan dalam mendapatkan laba yang optimal. Keberhasilan dari suatu perusahaan dapat dilihat dari kinerja keuangan dan bagaimana kondisi keuangan perusahaan tersebut. Nilai perusahaan menujukkan bagaimana keadaan perusahaan di kemudian hari, oleh sebab itu nilai perusahaan bisa menjadi cara bagi para investor untuk menilai bagaimana prospek dari perusahaan tersebut.

Profitable adalah suatu keadaan yang diwajibkan bagi perusahaan, agar bisa terus melaksanakan kegiatan operasinya. Apabila sebuah perusahaan hanya memiliki sedikit profit, maka perusahaan berisiko mengalami kendala yang cukup berarti untuk menggaet sumber pendanaan dari pihak eksternal. Ada beberapa hal yang bisa membuat nilai perusahaan naik maupun turun, yaitu Struktur Modal atau bisa disebut DER, Profitabilitas atau ROE, serta Ukuran Perusahaan atau Size.

Banyak faktor yang bisa membuat nilai perusahaan mengalami kenaikan dan penurunan, di antaranya yaitu struktur modal. Sebagaimana yang disebut oleh (Dhani \& Utama, 2017) adalah perbandingan antara sumber pendanaan dengan utang perusahaan. Lalu ada faktor berikutnya yaitu profitabilitas, yang digunakan oleh investor dengan tujuan melihat seberapa mampu perusahaan dalam meraup laba. Dan faktor selanjutnya yang dapat mempengaruhi nilai perusahaan yaitu ukuran perusahaan yang dapat dilihat dari total aktiva perusahaan itu sendiri.

Tabel 1 Data DER dan PBV Pada Perusahaan CEKA, INDF

\begin{tabular}{llllllll}
\multirow{2}{*}{ KODE } & \multicolumn{3}{c}{ DER } & \multicolumn{3}{c}{ PBV } \\
\cline { 3 - 7 } & & 2016 & 2017 & 2018 & 2016 & 2017 & 2018 \\
\hline $\mathbf{1}$ & CEKA & 0.61 & 0.54 & 0.32 & 0.90 & 0.85 & 0.89 \\
\hline $\mathbf{2}$ & INDF & 0.87 & 0.88 & 0.98 & 1.55 & 1.43 & 1.35 \\
\hline Sumber: $i d x$.co.id & & & &
\end{tabular}

Pada tabel 1 data memperlihatkan di mana struktur modal pada perusahaan CEKA pada tahun 2016-2017 mengalami peningkatan namun nilai perusahaan justru memperlihatkan grafik penurunan. Pada tahun 2017-2018 perusahaan CEKA mengalami penurunan tetapi nilai perusahaan tersebut justru mengalami kenaikan. Struktur modal INDF pada tahun 2016-2017 yang ditunjukan oleh table 1 mengalami peningkatan yang cukup baik tetapi pada tahun 2016-2017 nilai perusahaan tersebut justru mengalami penurunan. Pada tahun 2017-2018 struktur modal perusahaan INDF mengalami kenaikan lagi tetapi nilai perusahaan justru mengalami penurunan lagi.

Tabel 2. Data ROE dan PBV Pada Perusahaan CEKA, MLBI, dan BTEK

\begin{tabular}{cccccccc}
\cline { 3 - 8 } & \multirow{2}{*}{ KODE } & 2016 & 2017 & 2018 & 2016 & 2017 & 2018 \\
\hline & CEKA & 28.12 & 11.9 & 4.48 & 0.90 & 0.85 & 0.89 \\
\hline $\mathbf{2}$ & MLBI & 119.680 & 124.150 & 95.40 & 47.54 & 27.06 & 40.24 \\
\hline $\mathbf{3}$ & BTEK & 0.15 & -2.16 & 3.88 & 1.49 & 3.17 & 2.95 \\
\hline
\end{tabular}

Sumber: idx.co.id

Didasari oleh tabel 2 data member tahu profitabilitas perusahaan CEKA mengalami penurunan pada tahun 2016-2017, namun di tahun 2016-2017 nilai perusahaan justru menunjukan grafik kenaikan. Lalu dari tabel 1.2 kita juga dapat melihat profitabilitas pada tahun 2016-2017 MLBI pada tahun 2016-2017 mengalami kenaikan namun nilai perusahaan justru mengalami penurunan. Sedangkan pada tahun 2016-2017 BTEK mengalami penurunan tetapi nilai perusahaan mengalami pelonjakan pada tahun 20162017. Pada tahun 2017-2018 profitabilitas CEKA anjlok, namun nilai perusahaan pada 
tahun 2017-2018 megalami kenaikan. Pada perusahaan MLBI pada tahun 2017-2108 mengalami penurunan namun nilai perusahaan mengalami kenaikan.Lalu profitabilitas pada perusahaan BTEK tahun 2017-2018 mengalami kenaikan namun nilai perusahaan pada tahun 2017-2018 mengalami penurunan.

Tabel 3.Data Size, dan PBV Pada Perusahaan ULTJ, CEKA, dan ALTO

\begin{tabular}{llllllll}
\cline { 3 - 7 } & \multirow{2}{*}{ KODE } & \multicolumn{3}{c}{ SIZE } & \multicolumn{3}{c}{ PBV } \\
\cline { 2 - 7 } & & 2016 & 2017 & 2018 & 2016 & 2017 & 2018 \\
\hline $\mathbf{1}$ & ULTJ & 4.239 .200 & 5.186 .940 & 5.584 .546 & 3.95 & 3.59 & 3.32 \\
\hline $\mathbf{2}$ & CEKA & 1.425 .964 & 1.392 .636 & 1.211 .593 & 0.90 & 0.85 & 0.89 \\
\hline $\mathbf{3}$ & ALTO & 1.165 .094 & 1.109 .384 & 1.089 .609 & 0.01 & 1.86 & 2.29 \\
\hline
\end{tabular}

Sumber: idx.co.id

Seperti yang ditunjukkan tabel 3 data ukuran perusahaan (size) perusahaan ULTJ tahun 2016-2017 mengalami peningkatan, akan tetapi nilai perusahaan ULTJ mengalami keanjlokan. Lalu pada tahun 2016-2017 ukuran perusahaan (size) CEKA dan ALTO mengalami penurunan namun nilai perusahaan mengalami kenaikan. Pada tahun 20162017 ukuran perusahaan (size) ULTJ mengalami kenaikan namun pada tahun 2017-2018 nilai perusahaan mengalami penurunan. Lalu pada tahun 2017-2018 ukuran perusahaan (size) CEKA dan ALTO mengalami penurunan namun nilai perusahaan CEKA dan ALTO justru mengalami kenaikan. Tujuan Penelitian ini adalah untuk mengetahui pengaruh Struktur Modal, Profitabilitas dan Ukuran Perusahaan Terhadap Nilai Perusahaan.

\section{METODE PENELITIAN}

Nilai perusahaan adalah Variabel dependen pada penelitiann ini. Nilai perusahaan adalah tolok ukur penanam modal pada level kesuksesan perusahaan di mana berkaitan dengan harga saham, namun jika harga saham perusahaan tinggi, begitu pula yang akan terjadi dengan nilai perusahaan, hal ini dapat memperlihatkan kesejahteraan dari pemegang sahamnya. Penelitian ini mengindikasi nilai perusahaan dengan $P B V$ :

$$
\text { Rasio } P B V=\frac{\text { Harga Saham Per Lembar }}{\text { Nilai Buku Per Lembar }}
$$

Struktur Modal yaitu proporsi dalam pemenuhan kebutuhan pendanaan perusahaan yang diperoleh dari komparasi antara utang dengan modal sendiri. Pada penelitian ini indikator struktur modal diketahui ukurannya menggunakan Debt Equity Ratio dan bisa dirumuskan sebagai berikut :

$$
\text { Rasio Hutang Terhadap Ekuitas }=\frac{\text { Total Utang }}{\text { Total Modal }}
$$

Profitabilitas yaitu tingkatan dari seberapa mampu perusahaan dalam meraih laba yang dapt ditunjukkan dengan hasil yang diperoleh penjualan dan investasi perusahaan yang dapat menunjukkan keberhasilan perusahaan. Penelitian ini pun mengindikasi profitabilitas dengan memakai Return On Equity dan dapat diperoleh dari rumus di bawah ini:

$$
\text { Pengembalian Atas Ekuitas }=\frac{\text { Laba Bersih Setelah Pajak }}{\text { Total Ekuitas }}
$$

Ukuran Perusahaan Yaitu suatu indikator yang bisa dipakai guna mengetahui ukuran kerja dari satu perusahaan yang bisa dilihat dari seberapa besar perusahaan tersebut karena dapat memengaruhi bagaimana perusahaan dalam mendapatkan pendanaan. Di penelitian ini indikator ukuran perusahaan diukur memakai Size dan dapat dirumuskan sebagai berikut :

\section{Pengembangan Hipotesis}

$$
\text { Size }=\operatorname{Ln}(\text { Total Aktiva })
$$

Pengaruh Struktur Modal dan Nilai Perusahaan. Hubungan struktur modal dengan nilai perusahaan juga dibahas oleh Hirdinis (2019) "capital structure is key to improving
Company Value and Food Beverage Manufacturer 
Company Value and Food Beverage Manufacturer productivity and company performance. Capital structure theory explain that the company's financial policy in determining capital structure (mix between debt and equity) aims to optimize the value of the company (value of the firm)". Irfan Fahmi (2011) juga mengatakan bahwa tujuan strukur modal ialah menggunakan sumber dana permanen yang selanjutnya bisa dipakai perusahaan guna memaksimumkan nilai perusahaan. Menguatkan kestabilan keuangan adalah poin penting dari sebuah perusahaan, karena perubahan struktur modal dapat berakibat perubahan pada nilai perusahaan itu sendiri. Penurunan nilai dari perusahaan dapat memengaruhi nilai dari saham. H1 : Struktur Modal berpengaruh terhadap Nilai Perusahaan

Pengaruh Profitabilitas dan Nilai Perusahaan. Profitabilitas bisa dipergunakan sebagai indikator untuk menunjukkan bagaimana kinerja perusahaan. Profitabilitas memengaruhi nilai perusahaan. Jika profitabilitas perusahaan dalam keadaan baik maka hal ini berpengaruh positif terhadap keputusan penanam modal dalam menaruhkan sahamnya. Jika laba meningkat begitu juga harga saham dipasar pun mengikuti tren peningkatan, yang juga terjadi dengan kepercayaan investor. Jika profitabilitas yang dimiliki perusahaan tinggi berarti hal ini dapat menjadi pertanda baik untuk para investor karena jika profitabilitas perusahaan berada di titik yang bagus maka perusahaan tersebut dapat dikategorikan dalam keadaan yang stabil dengan demikian investor semakin tertatik untuk berinvestasi di perusahaan tersebut. H2 : Profitabilitas berpengaruh terhadap Nilai Perusahaan

Pengaruh Ukuran Perusahaan dan Nilai Perusahaan. Bahwa melihat kecil besarnya perusahaan bisa melalui total aset atau total penjualannya. Manajemen juga dapat memberitahukan total asset atau jumlah transaksi penjualan terhadap investor agar penanam saham mampu melihat bagaimana prospek perusahaan tersebut di masa depan. Perusahaan yang masif dianggap mampu mengelola perusahaan dengan baik, besarnya perusahaan juga dapat lebih mudah untuk memperoleh pendanaan hal ini bisa mempengaruhi nilai perusahaan. Besarnya ukuran perusahaan juga akan memperlihatkan tingkat keuntungan perusahaan dimasa yang akan datang. H3 : Ukuran Perusahaan berpengaruh Terhadap Nilai Perusahaan

\section{Populasi dan Sampel}

Populasi yang dipakai demi berlangsungnya penelitian ialah industry yang namanya tercatat dan tercantum dalam Bursa Efek Indonesia (BEI) dengan periode pengambilan data yang diteliti pada Tahun 2016 - 2018. Sampel yang digunakan yaitu Perusahaan sub sektor Makanan dan Minuman di Bursa Efek Indonesia (BEI) dengan periode tahun 2016 - 2018 adalah sampel yang digunakan pada penelitian ini. Teknik sampling yang dipakai yaitu non probability sampling, teknik yang digunakan bagi setiap anggota populasi tidak memiliki peluang atau kesempatan yang sama. purposive sampling menjadi teknik non probability sampling yang digunakan.

\section{HASIL DAN PEMBAHASAN}

Tabel 4 Karakteristik dan Kriteria Sampel

\begin{tabular}{rll}
\hline No. & Kriteria Pemilihan Sampel & Jumlah \\
\hline 1 & $\begin{array}{l}\text { Perusahaan subsektor Makanan dan Minuman yang terdaftar di } \\
\text { Bursa Efek Indonesia }\end{array}$ & 24 \\
\hline 2 & $\begin{array}{l}\text { Perusahaan subsektor Makanan dan Minuman yang tidak konsisten } \\
\text { mempublikasikan laporan keuangan secara lengkap pada tahun }\end{array}$ & $(7)$ \\
& \\
\hline 2016-2018. & $\begin{array}{l}\text { Perusahaan subsektor Makanan dan Minuman yang memperoleh } \\
\text { rugi selama periode tahun 2016 - 2018 }\end{array}$ \\
\hline Total keseluruhan Perusahaan yang mencakup karakteristik dan criteria & 12 \\
\hline Total tahun pengamatan & 3 \\
\hline Total keseluruhan sampel selama periode penelitian & 36 \\
\hline
\end{tabular}


Berdasarkan tabel diatas, melalui teknik pemilihan sampel menggunakan non probability sampling yaitu purposive sampling, maka terpilih 12 perusahaan. Sub sektor makanan dan minuman untuk diijadikan sampeli penelitian dengan periodei penelitian 3 tahun, sehinggaidapat diperoleh total sampel menjadi 36 data penelitian.

\section{Analisis Statistik Deskriptif}

Menjabarkan data yang dapat ditinjau dari maksimum, minimum, standar deviasi, dan nilai rata-rata dari masing-masing setiap varibael dalam suatu penelitian. Di penelitian ini, nilai perusahaan menjadi varibael dependen. Variabel independen pada penelitian ini yaitu Struktur Modal (DER), Profitabilitas (ROE), dan Ukuran Perusahaan (Size). Data yang digunakan pada penelitian adalah data sekunder yang diperoleh dari laporan keuangan tahunan yang dikemukakan pada publik oleh BEI.

Tabel 5 Hasil Statistik Deskriptif

\begin{tabular}{lcccc}
\hline & PBV & DER & ROE & SIZE \\
\hline Mean & 5.381503 & 0.798655 & 21.29487 & 28.90564 \\
Median & 3.285221 & 0.760131 & 12.72567 & 28.51677 \\
Maximum & 30.16822 & 1.772273 & 125.3257 & 32.23018 \\
Minimum & 0.677602 & 0.163544 & 0.900697 & 27.06574 \\
Std. Dev. & 4.506154 & 0.467142 & 20.29502 & 1.483686 \\
Observations & 36 & 36 & 36 & 36 \\
\hline
\end{tabular}

Sumber: Data diolah dari E-Views 10

\section{Nilai Perusahaan (PBV)}

Pada tabel di atas bisa diketahui bahwa sampeli yang dipakaii dalam penelitian inii sejumlah 36 data observasii. Lalu dari sampel dapat diketahui bahwa nilai perusahaan pada sub sektor makanan dan minuman di Bursa Efek Indonesia pada periode 2016-2018 memiliki rata-rata (mean) sebesar 5.381503 dari 12 sampel perusahaan selama periode 2016-2018. Nilai perusahaan tertinggi (Maksimum) yaitu 30.16822 yang diperoleh dari perusahaan MLBI (Multi Bintang Indonesia Tbk) pada tahun 2016. Lalu nilai perusahaan terendah (Minimum) yaitu 0.677602 yang diperoleh dari perusahaan INDF (Indofood Sukses Makmur Tbk) pada tahun 2018. Kemudian untuk standar deviasi yang didapatkan untuk variabel nilai perusahaan sebesar 5.506154 yang berada di bawah rata-rata (mean) dan mendekati 0 (nol), berartii data yang dipakai dalam kondisi prima.

\section{Struktur Modal (DER)}

Dari tabel di atas bisa dipandang bahwa stuktur modal pada Bursa Efek Indonesia yang berkecimpung di sub sektor makanan dan minuman pada periode 2016-2018 memiliki rata-rata (mean) sebesar 0.798655 dari 12 sampel perusahaan selama periode 2016-2018. Struktur Modal tertinggi (Maksimum) yaitu 1.772273 yang diperoleh dari perusahaan MLBI (Multi Bintang Indonesia Tbk) pada tahun 2016. Lalu struktur modal paling rendah yaitu 0,163543915 yang diperoleh dari perusahaan ULTJ (Ultra Jaya Milk Industry \& Trading Company Tbk) di tahun 2018. Kemudian untuk standar deviasi yang didapatkan untuk variabel struktur modal sebesar 0.467142 yang berada dibawah ratarata (mean) dan mendekati 0 (nol), berarti data yang dipakai dalam kondisi baik.

\section{Profitabilitas (ROE)}

Diperhatikan dari table di atas, dapat dilihat bahwa profitabilitas di Bursa Efek Indonesia yang bergerak pada sub sektor makanan dan minuman pada periode 2016-2018 memiliki rata-rata (mean) sebesar 21.29487 dari 12 sampel perusahaan selama periode 2016-2018. Profitabilitas tertinggi (Maksimum) yaitu 125.3256928 diperoleh dari perusahaan MLBI (Multi Bintang Indonesia Tbk) di tahun 2016. Lalu profitabilitas terendah (Minimum) yaitu sebesar 0.900696565 perusahaan SKLT (Sekar Laut Tbk) di Tahun 2018. Kemudian untuk standar deviasi yang didapatkan untuk variabel profitabilitas sebesar 20.29502 yang berada di bawah rata-rata (mean) dan mendekati 0 (nol), berarti data yang dipakai dalam kondisi baik

\section{Ukuran Perusahaan (Size)}

Dari tabel diatas dapat dilihat sseberapa besaran perusahaan pada sub sektor makanan dan minuman di Bursa Efek Indonesia pada periode 2016-2018 memiliki rata-rata (mean)
Financial Behavior and Small Medium Enterprises

\section{3}


Company Value and Food Beverage Manufacturer sebesar 28.90564 dari 12 sampel perusahaan selama periode 2016-2018. Ukuran Perusahaan tertinggi (Maksimum) yaitu 32.23018 diperoleh dari perusahaan INDF (Indofood Sukses Makmur Tbk) 2016. Lalu ukuran perusahaan terendah (Minimum) yaitu sebesar 27.06574 perusahaan STTP (Siantar Top Tbk) pada tahun 2018. Kemudian untuk standar deviasi yang didapatkan untuk variabel ukuran perusahaan sebesar 1.483686 yang berada di bawah rata-rata (mean) dan mendekati 0 (nol), berarti data yang dipakai dalam kondisi baik.

\section{Pemilihan Model Regresi Data Panel}

Didasari oleh hasili uji-uji yang telah selesai dilaksanakani, maka Fixed Effect Model (FEM). dapat menjadi model paling tepat iyang bisa dipakai di dalam penelitiani ini. Didasari pula dengan hasil perhitungan analisis pengaruh variabel independen terhadap variabel dependen, maka dapat dijelaskan sebagai berikut:

Tabel 6 Fixed Effect Model

\begin{tabular}{|lrrrr|}
\hline Variable & Coefficient & \multicolumn{1}{c|}{ Std. Error } & \multicolumn{1}{c|}{ t-Statistic } & \multicolumn{1}{c|}{ Prob. } \\
\hline C & -6.363826 & 11.06162 & -0.575307 & 0.5712 \\
Struktur Modal & 3.602246 & 1.084295 & 3.322202 & 0.0032 \\
Profitabilitas & 0.211418 & 0.016707 & 12.65447 & 0.0027 \\
Ukuran Perusahaan & 0.151052 & 0.386293 & 0.391030 & 0.6997 \\
\hline
\end{tabular}

Sumber: Data diolah dari E-Views 10

Didasari oleh table di atas hasil pengujian terhadap model regresi data panel, lalu dapat dituliskan persamaan regresi data panel seperti berikut :

a. Konstanta . Berdasarkan hasil uji regresi, dapat diketahui konstanta sebesar 6.363826 yang menyatakan bahwa tanpa adanya pengaruh dari variabel independen yaitu profitabilitas, struktur modal, dan ukuran perusahaan maka nilai dari perusahaan akan menurun sebesar 6.363826 .

b. Koefisien regresi Struktur Modal. Nilai koefisien regresi variabel struktur modal yang di ukur dengan Debt Equity Ratio (DER) sebesar 3.602246. Hal ini menyatakan bahwa setiap kenaikan dengan Debt Equity Ratio (dengan asumsi bahwa varibael lainnya konstan)akan meningkat sebesar 3.602246. Koefisien regresi variabel struktur modal bernilai positif yang berarti bahwa adanya hubungan antara Debt Equity Ratio dengan Nilai Perusahaan yang positif.

c. Koefisien regresi Profitabilitas. Nilai koefisien regresi variabel struktur modal yang di ukur dengan Return On Equity (ROE) sebesar 0.211418. Hal ini menyatakan bahwa setiap kenaikan dengan Return On Equity(dengan asumsi bahwa varibael lainnya konstan), akan meningkat sebesar 0.211418 . Koefisien regresi variabel struktur modal bernilai positif yang berarti bahwa adanya hubungan positif antara Return On Equity dengan Nilai Perusahaan.

d. Koefisien regresi Ukuran Perusahaan. Nilai koefisien regresi variabel struktur modal yang di ukur dengan Size sebesar 0.151052. Hal ini menyatakan bahwa setiap kenaikan dengan Size (dengan asumsi bahwa varibael lainnya konstan), maka akan meningkat sebesar 0.151052. Koefisien regresi variabel struktur modal meenghasilkan nilai positif berarti bahwa adanya hubungan yang positif antara Size dengan Nilai Perusahaan.

\section{Uji Hipotesis}

Uji Parsial (Uji t). Penggunaan Uji t dalam pengujian ini ini bermaksud untuk menggali infoormasi tentang pengaruh variabel independen, yaitu Struktur Modal (X1), Profitabilitas (X2), dan Ukuran Perusahaan (X3) secara parsial terhadap variabel dependen yaitu Nilai Perusahaan (Y). Pengambilan Keputusan dalam uji hipotesis ini dapat dikuru dengan melakukan perbandingan antara nilai probabilitas atau signifikan atau nilai kritisnya. Jika nilai probabilitas $<$ nilai kritis atau nilai probabilitas $<0.05$ atau $5 \%$, maka $\mathrm{H} 0$ tidak diterima dan $\mathrm{H} 1$ diterima. Berarti variabel dependen dipengaruhi oleh variabel independen. Tetapi jika nilai probabilitas $>$ nilai kritis atau nilai probabilitas $>$ 0.05 atau 5\%, maka $\mathrm{H} 0$ diterima dan $\mathrm{H} 1$ tidak diterima, yang berarti bahwa varibel 
independen tidak memiliki pengaruh terhadap variabel dependen. Di bawah ini dipaparkan hasil dari uji t (Parsial).

Tabel 7 Hasil Uji t

\begin{tabular}{|lllll|}
\hline Variable & Coefficient & Std. Error & t-Statistic & Prob. \\
\hline C & -6.363826 & 11.06162 & -0.575307 & 0.5712 \\
Struktur Modal & 3.602246 & 1.084295 & 3.322202 & 0.0032 \\
Profitabilitas & 0.211418 & 0.016707 & 12.65447 & 0.0027 \\
Ukuran Perusahaan & 0.151052 & 0.386293 & 0.391030 & 0.6997 \\
\hline
\end{tabular}

Financial Behavior and Small Medium

Enterprises

Sumber: Data diolah dari E-Views 10

a. Pernyataan pengaruh Struktur Modal pada Nilai Prusahaan menggunakani DER, memperlihatkani nilai signifikansiii yang lebihii kecili dariii $\alpha(0.0032<0.05)$ serta struktur modal memilikii pengaruhi positiif sebesari 3.602246 serta mempunyai nilai dari thitung $>$ ttabel yaitu $3.322202>2.03693(\mathrm{df}=36-4=32)$. Sehingga, H0 ditolak dan Ha diterima yang berarti Struktur Modal member pengaruh baik terhadap nilai perusahaan

b. Pengaruh Profitabilitas pada Nilai Perusahaan yang dinyatakan dengan ROE, menunjukkan nilai signifikansi lebih kecil dari $\alpha(0.0027<0.05)$ serta profitabilitas memilikiii pengaruhi positif sebesar 0.211418 serta mempunyai nilai dari thitung> ttabel yaitu $12.65447>2.03693(\mathrm{df}=36-4=32)$. Sehingga, H0 ditolak dan Ha diterima dan bisa dibilanngi Profitabilitasi memberi dampaki baik pada nilai perusahaan

c. Pernyataan pengaruh Ukuran Perusahaan terhadapi Nilai Perusahaan bisa dengan Size, menunjukkan nilai signifikansi yang lebih besar dari $\alpha(0.6997>0.05)$ dan ukuran perusahaan mempunyai pengaruh baik atau psoitif sebesar 0.151052 dan mempunyai nilai dari thitung $<$ ttabel yaitu $0.391030<2.03693(\mathrm{df}=36-4=32)$.

Sehingga, H0 diterima dan Ha ditolak yang berarti Ukuran Perusahaan tidak berpengaruh terhadap Nilai perusahaan.

Uji Koefisien Determinasi $\left(\mathbf{R}^{2}\right)$. Uji dilaksanakan guna melihat seberapa besarkah proporsi variabel dependen (Nilai Perusahaan) yang dijelaskan dengan variable independen (Struktur Modal, Profitabilitas serta Ukuran Perusahaan). Besaran koefisien determinasi akan sebanding dengan besar variabel independen dalam menjelaskan variabel dependen. Nilai Adjusted $R^{2}$ digunakan peneliti untuk bisa tahu akan model apakah yang tepat untuk dipakai. Didasari oleh hasil pengujian dari koefisien determinasi $\mathrm{R}^{2}$ dituailah hasil sebagai berikut:

Tabel 8 Hasil Koefisien Determinasi $\left(\mathrm{R}^{2}\right)$

\begin{tabular}{ll}
\hline $\mathrm{R}$-squared & 0.950578 \\
Adjusted R-squared & 0.917630
\end{tabular}

Sumber: Data diolah dari E-Views 10

Dilihat melalui tabel di atas, Adjusted $R^{2}$ sebesar 0.917630 menjadi nilai koefisien determinasi yang digunakan, hal ini menunujukkan bagaimana variabel independen yaitu Struktur Modal, Profitabilitas dan Ukuran Perusahaan dapat menjelaskan 91,76\% pada jumlah varian variabel dependen yaitui nilaii perusahaann. Dan sisa yang sebesar $8,24 \%$ dijelaskan oleh variabel lainnya di mana tidak digunakan dalam penelitian ini.

Pembahasan

Pengaruh Struktur Modal Terhadap Nilai Perusahaan. Didasari oleh hasil regresii data panel memperlihatkan di mana nilaii koefisien struktur modal yang dicari ukurannya menggunakan Debt Equity Ratio (DER) mempunyai thitung $>$ ttabel yaitu $3.322202>$ $2.03693(\mathrm{df}=36-4=32$ ) yang menunjukkan struktur modal cukup memengaruhi nilai perusahaan dana memiliki nilai signifikan yang didapat sebesar $0.0032<0.05$. Struktur modal adalah komparasi antara total utang dengan modal sendiri. Perusahaan dengan struktur modal yang tinggi dapat menunjukkan bahwa perusahaan tersebut mrmiliki prospek yang bagus sehingga dapat meningkatkan nilai perusahaan. Menurut Ramdhonah, $\mathrm{dkk}(2019)$ menggunakan utang didalam struktur modal perusahaan bisa 
Company Value and Food Beverage Manufacturer menaikkan nilai perusahaan karena menurut penanam modal menggunakan utang yang dilakukan oleh perusahaan dapat menunjukkan kepada penanam modal bahwa perusahaan tersebut memiliki prospek yang baik pada masa yang akan datang, lalu jika perusahaan tersebut mendapatkan pinjaman itu berarti perusahaan tersebut mampu memenuhi kewajibannya di masa depan sesuai dengan beberapa ketentuan yang diberikan oleh pemberi pinjaman tersebut.

Hasil penelitian ini sejalan dengan penelitian sebelumnya yang telah dilakukan oleh Yanti dan Damayanti (2019) serta Apriada dan Suardhika (2016) yang menyatakan bahwa DER memengaruhi kenaikkan Nilaii Perusahaani. Maka bia disimpulan jika DER dapat memengaruhi Nilai Perusahaan

Pengaruh Profitabilitas Terhadap Nilai Perusahaan. Didasari oleh hasil regresi data panel memperlihatkan bahwa nilai koefisien profitabilitas yang dikur deng Return On Equity mempunyai thitung > ttabel yaitu $12.65447>2.03693(\mathrm{df}=36-4=32)$ hal ini menunjukkan bahwa profitabilitas memengaruhi nilai perusahaan bernilai signifikan yang didapatkan sebesar $0.0027<0.05$. Profitabilitas yang tinggi bisa menunjukkan kepada investor bahwa modal yang ditanamkan oleh investor dikelola dengan baik oleh perusahaan. Profitabilitas menjadi salah satu alat evaluasi bagi perusahaan apakah selama ini perusahaan sudah berjalan dengan efektif atau belum dan profitabilitas dapat digunakan sebagai tolok ukur bagi investor karena jika tingkat profitabilitas perusahaan tinggi maka nilai perusahaan juga akan tinggi hal ini dapat membuat investor semakin yakin dalam menaruhkan sahamnya di perusahaan tersebut. Jika kondisi perusahaan dalam keadaan baik dalam arti memiliki kondisi yang menguntungkan pada masa yang akan datang maka akan semakin banyaknya penanam modal yang akan menanamkan sahamnya di perusahaan tersebut karena hal ini dapat mendorong harga saham menjadi lebih tinggi dan akan mempengaruhi nilai seberapa tingginya nilai perusahaan. Hasil penelitian ini berjalan beriringan dengan penelitian sebelumnya yang telah dilakukan oleh Nanang dan Nisa (2017), serta Ramdhonah, dkk (2019) yang berkesimpulan bahwa ROE berpengaruh positif terhadap Nilai Perusahaan. Maka dapat disimpulan bahwa ROE bisa memengaruhi Nilai Perusahaan.

Pengaruh Ukuran Perusahaan Terhadap Nilai Perusahaan. Dari hasil regresii data panel membuktikan jika nilaii koefisiensi ukuran perusahaan yang diketahui ukurannya dengan Size mempunyai thitung $<$ ttabel yaitu yaitu $0.391030<2.03693(\mathrm{df}=36-4=$ 32). Sehingga, H3 ditolak yang berarti Ukuran Perusahaan tidak memengaruhi Nilai perusahaan dengan nilai signifikan yang didapatkan sejumlah $0.6997>0.05$. Hal tersebut memberi petunjuk bahwa besaran perusahaan yang masif tidak mudah untuk menggali sumber pendanaan untuk meningkatkan nilai perusahaan. Seberapa besar ukuran perusahaan akan berbanding lurus dengan kebutuhan perusahaan pada banyaknya guna kegiatan operasi sehari-hari. Salah satu hulu dana yang bisa dituai perusahaan yaitu hutang yang berhulu dari pihak luar. Sehingga semakin besarnya perusahaan akan semakin besar juga hutang yang dimiliki oleh perusahaan. Penarikan hutang yang dilaksnaakan oleh perusahaan besar sebaiknya bisa menjadikan perusahaan mendapatkan pengembalian aset yang lebih besar juga. Aset yang digunakan sebagao jaminan untuk mendapatkan utang nilainya lebih masif dari pada pengembalian asetnya yang diterima perusahaan. Ini dapat memperlihatkan kurangnya solvabilitasnya antar asset dengan utang yang dapat membuat para investor menjadi khawatir. Jika hal ini terus meningkat akan perusahaan akan berpotensi besar untuk mengalami kebangkrutan.

Hasil penelitiani inii juga berjalan seiringan dengani riseti sebelumnyai yang telah dikerjakan oleh Dewi dan Sudiartha (2017), serta Wulandari dan Wiksuana(2017) yang mengatakan Ln Total Asset (Size) tidak memengaruhi Nilai Perusahaan. Oleh sebab itu dapaat disimpulan bahwa Size (Ln Total Asset) tidak bisa dijadikan sebagai faktor yang memengaruhi Nilai Perusahaan. 


\section{PENUTUP}

Financial Behavior

Penelitian ditujukan agar mampu untukk tahu akan Struktur Modal, Profitabilitas serta Ukuran Perusahaan terhadap Nilai Perusahaan. Sampel yang dipakai untuk penelitian ini yaitu subsektor makanan dan minuman periode 2016-2018. Metode yang dipakai untuk penelitian ini ialah purposive sampling, sehingga sampel akhir yang dipergunakan pada penelitian ini adalaha 12 perusahaan. Dalam penelitian ini data didapat melalui data sekunder yang berasal dari website Bursa Efek Indonesia. Teknik analisis data yang digunakan yaitu analisis regresi data panel dan statistik deskriptif dengan pertolongan aplikasi Micrisift Excel 2013 dan E-Views version 10. Didasari oleh and Small Medium

Enterprises hasil analisis tersebut menjelaskan bahwa:

a. Metode pengukuran Debt to Equity Ratio memberikan hasil pengujian berupa variabel Struktur Modal berpengaruh signifikan terhadap nilai perusahaan pada sub sektor makanan dan minuman yang terdaftar di Bursa Efek Indonesia periode 2016-2018. Maka bisa disimpulkan bahwa hipotesis dalam penelitian ini terbukti.

b. Pengukuran ujii variabel profitabilitas dengan Return on Equity melahirkan hasil yang menyatakan profitabilitas berpengaruh signifikan terhadap nilai perusahaan pada subsektor makanan dan minuman yang terdaftar di Bursa Efek Indonesia periode 2016-2018. Maka dari itu disimpulkan bahwa hipotesis pada penelitian ini memiliki nyata

c. Pengukuran uji variabel ukuran perusahaann menggunakan Size menciptakan sebuah hasil yang menunjukkan bahwa Ukuran Perusahaan tidak memengaruhu nilai perusahaan secara signifikan pada subsektor makanan dan minuman yang terdaftar di Bursa Efek Indonesia periode 2016-2018. Maka dari itu dapat disimpulkan bahwa hipotesis tidak terbukti di penelitian ini.

\section{DAFTAR PUSTAKA}

[1] Ambarwati, S. D. (2010). Manajemen Keuangan Lanjutan. Yogyakarta: Graha Ilmu.

[2] Anggriawan, F., Topowijono, \& Sudjana Nengah. (2017). Pengaruh Struktur Modal Terhadap Nilai Perusahaan Pada Perusahaan Sub Sektor Makanan dan Minuman Yang Listing Di Bursa Efek Indinesia Tahun 2011-2015. Jurnal Administrasi Bisnis, 50(4), 105-114.

[3] Antwi, S., Mills , E. F., \& Zhao, P. X. (2012). Capital Structure adn Firm Value: Empirical Evidence From Ghana. International Journal Of Business and Social Science, 3(22), 103-111.

[4] Dhani, I. P., \& Utama, A. G. (2017). Pengaruh Pertumbuhna Perusahaan, Struktur Modal, dan Profitabilitas Terhadap Nila Perusahaan. Jurnal Riset Akuntansi dan Bisnis Airlangga, 2(1), 135-148.

[5] Fajrina, A. (2016). Pengaruh Corporate Social Responsibility, Keputusan Investasi dan Struktur Modal dan Kinejra Keuangan Terhadap Nilai Perusahaan. Jurnal Nominal, 5(2), 16-28.

[6] Fauziah, F. (2017). Kesehatan Bank, Kebijakan Deviden dan Nilai Perusahaan. Samarinda: RV Pustaka Horizon.

[7] Febriana, D., \& Yulianto, A. (2017). Pengujian Pecking Order Theory Di Indonesia. Management Analysis Journal, 6(2), 153-165.

[8] Franita, R. (2018). Mekanisme Good Corporate Governance Dan Nillai Perusahaan Studi Untuk Perusahaan Telekomunikasi. Medan: Lembaga Penelitian Dan Penulisan Ilmiah Aqli.

[9] Hadiningrat, E., Mangantar, M., \& Pondaag, J. (2017). Analisis Pengaruh Rasio Likuiditas dan Rasio Profitabilitas Terhadap Return Saham Pada Perusahaan LQ 45. Jurnal EMBA, 5(2), 2349-2375. 
Company Value and Food Beverage Manufacturer
[10] Haryadi, E. (2016). Pengaruh Size Perusahaan, Keputusan Pendanaan, Profitabilitas, dan Keputusan Investasi Terhadap Nilai Perusahaan. Jurnal Akuntansi, 3(2), 84-100.

[11] Hirdinis. (2019). Capital Structure and Firm Size On Firm Value Moderated by Profitability. International Journal Of Economics and Business Administration, 7(1), 174-191.

[12] Indrarini, S. (2019). Nilai Perusahaan Melalui Kualitas Laba. Surabaya: Scopindo.

[13] Karasek, R., \& Brayant, P. (2012). Signaling Theory: Past, Present, and Future. Academy Of Strategic Management Journal, 11(1), 91-100.

[14] Manopo, H., \& Arie, F. V. (2016). Pengaruh Sturktur Modal, Ukuran Perusahaan dan Profitabilitas Terhadap Nilai Perusahaan Otomotif yang Terdaftar di Bursa Efek Indonesia Periode 2011-2014. Jurnal EMBA, 4(2), 485497.

[15] Murnita, P. E., \& Putra, I. P. (2018). Pengaruh Corporate Social Responsibility Terhadap Nilai Perusahaan dengan Profitabilitas dan Leverage sebagai Variabel Pemoderasi. E-Jurnal Akuntansi Universitas Udayana, 23(2), 1470-1494.

[16] Musthafa. (2017). Manajemen Keuangan. Yogyakarta: CV. Andi Offset.

[17] Pantow, M. S., Murni, S., \& Trang, I. (2015). Pengaruh Pertumbuhan Penjualan, Ukuran Perusahaan, Return On Asset dan Struktur Modal Terhadap Nilai Perusahaan Yang Tercatat di Indeks LQ 45. Jurnal EMBA, 3(1), 961-971.

[18] Samosir, H. E. (2017). Pengaruh Profitabilitas dan Kebijakan Utang Terhadap Nilai Perusahaan Yang Terdaftar Di Jakarta Islamic Index (JII). Journal Of Business Studies, 2(1), 75-83.

[19] Sari, D. M., Gustini, E., \& Tripermata, L. (2016). Pengaruh Struktur Modal dan Kinejra Keuangan Terhadap Nilai Perusahaan Pada Perusahaa

Perbankan Di Bursa Efek Indinesia. Jurnal Ilmiah Ekonomi Global Masa Kini, 7(3), 33-39.

[20] Sihombing, P. (2018). Corporate Financial Management. Bogor: PT Penerbit IPB Press.

[21] Syardiana, G., Rodoni, A., \& Putri, Z. E. (2015). Pengaruh Investmen Oppurtunity Set, Struktur Modal, Pertumbuhan Perusahaan, dan Return On Asset Terhadap Nilai Perusahaan. Jurnal Akuntabilitas, 8(1), 39-45.

[22] Tui, S., Nurnajamuddin, M., Sufri, M., \& Nirwana, A. (2017). Determinants Of Profitability and Firm Value: Evidence From Indonesian Banks. IRAInternational Journal of Management \& Social Sciences, 07(01), 84-95.

[23] Utomo, N. A., \& Christy, N. N. (2017). Pengaruh Struktur Modal, Profitabilitas, Ukuran Perusahaan Terhadap Nilai Perusahaan Pada Perusahaan LQ45 Di Bursa Efek Indonesia. Strategi Pengembangan Sumber Daya Manusia, 1(1), 398-415.

[24] Vaeza, N. D., \& Hapsari, D. W. (2015). Pengaruh Ukuran Perusahaan, Profitabilitas, Leverage dan Kebijakan Dividen Terhadap Nilai Perusahaan Pada Perusahaan Perbankan Di Bursa Efek Indonesia Periode 2010-2013. eProceeding Of Management, 2(3), 3310-3317.

[25] Yanti, I. G., \& Darmayanti, N. P. (2019). Pengaruh Profitabilitas, Ukuran Perusahaan, Struktur Modal, dan Likuiditas Terhadap Nilai Perusahaan Makanan dan Minuman. E-Jurnal Manajemen, 8(4), 2297-2324. 